\title{
INVESTIGATION OF THE TEMPERATURE ON THE THIN LAYERS OF COBALT OXIDE PRODUCED BY THE SPRAY PYROLYSIS METHOD USING A SOLAR OVEN
}

\author{
Abderrezak Gharbi ${ }^{1} *$, Said Benramache ${ }^{2}$, Lahcen Fellah ${ }^{3}$, Aziez Zedouri ${ }^{3}$ \\ ${ }^{1}$ Department of Drilling and Mechanics of Oil Works, Faculty of Hydrocarbons and Earth \\ Science and Renewable Energies, University of Ouargla, Algeria \\ ${ }^{2}$ Department of Material Sciences, Faculty of Sciences, University of Biskra, Algeria \\ ${ }^{3}$ Underground oil, gas and aquifer reservoirs Laboratory, University of Ouargla, Algeria \\ *Corresponding author: gharbi_abdou2000@yahoo.fr
}

\begin{tabular}{|c|c|}
\hline Article Info & Abstract \\
\hline $\begin{array}{l}\text { Received: } 10.09 .2021 \\
\text { Accepted: } 23.11 .2021 \\
\text { Keywords: } \\
\text { Co3O4, x-rays, optical gap, } \\
\text { spray, solar }\end{array}$ & $\begin{array}{l}\text { Thin films of cobalt oxide (Co3O4) were prepared on glass substrates by the } \\
\text { spray pyrolysis method using a solar concentrator (oven) manufactured in our } \\
\text { laboratory. We used different processing temperatures }\left(300^{\circ} \mathrm{C}, 350^{\circ} \mathrm{C} \text { and } 400^{\circ} \mathrm{C}\right) \text {. } \\
\text { The structural, optical and electrical properties of the different samples were analyzed } \\
\text { by X-ray diffraction (XRD), UV-Visible spectroscopy and the Hall effect } \\
\text { measurement system. X-ray diffraction observations revealed that cubic crystals are } \\
\text { created in all films produced, and the film structure is that of a single phase created } \\
\text { with preferential orientation along the (311) axis in films at low temperatures, and the } \\
\text { axis (111) for high temperatures. The grain sizes of our products vary between } \\
\text { (22.62nm and } 66.19 \mathrm{~nm}) \text {, depending on the processing temperature. The optical band } \\
\text { gap of the crystals obtained was measured. The results of the optical forbidden bands } \\
\text { of the crystals obtained, indicated two bands of the values for each element }(\text { Eg } 1 \text { and } \\
\text { Eg2). We observed that the values of the effective optical forbidden bands increase by } \\
2.547 \mathrm{eV} \text { and } 3.0731 \mathrm{eV} \text { with the increase in the production temperature. In addition } \\
\text { the film produced experiences a decrease in the Urbach parameters which vary } \\
\text { between } 162.20 \mathrm{meV} \text { and } 360.81 \text { meV depending on the increase in production } \\
\text { temperatures. Finally, the films produced have electrical conductivity values of }(1.090 \\
{\left[(\Omega . \mathrm{cm})^{-1}\right] \text { to } 1.853\left[(\Omega . \mathrm{cm})^{-1}\right] \text { and electrical resistivity values of } 1.431(\Omega . \mathrm{cm}) \text { at } 1.853} \\
(\Omega . \mathrm{cm}) \text {, depending on the variation in the production temperature. }\end{array}$ \\
\hline
\end{tabular}

\section{Introduction}

Cobalt oxide (Co3O4) is an ionic chemical compound, made by decomposing cobalt chloride hexahydrate. The species likely to form during the oxidation of $\mathrm{Co}(\mathrm{OH}) 2$ in a neutral and basic medium leads to the formation of $\mathrm{Co} 3 \mathrm{O} 4, \mathrm{Co} 2 \mathrm{O} 3$ or in hydrated form: $\mathrm{Co}(\mathrm{OH}) 3$ or $\mathrm{CoO} 2$ [1]. Cobalt oxide $\mathrm{Co} 2 \mathrm{O} 3$ is very metastable, its existence in the solid state has not yet been clearly verified [2]. Oxidation of $\mathrm{Co}(\mathrm{OH}) 2$ in air results in the formation of $\mathrm{Co} 2 \mathrm{O} 3$ and 
the reaction proceeds rapidly until $\mathrm{Co} 3 \mathrm{O} 4$ is obtained $[3,4]$. It crystallizes, at temperatures below $450^{\circ} \mathrm{C}$, in the cubic spinel structure in the same way as $\mathrm{Fe} 3 \mathrm{O} 4$ [5]. It has a face-centered cubic structure, the mesh parameter is $8.080 \AA$ and the space group $\mathrm{Fd} 3 \mathrm{~m}$ (type $\mathrm{Al} 2 \mathrm{MgO} 4$ ). Despite the simple stoichiometry of $\mathrm{Co3O} 4$, this spinel structure is much more complicated than $\mathrm{CoO}$. Unlike $\mathrm{CoO}$, this $\mathrm{Co} 3 \mathrm{O} 4$ structure has two kinds of ions: $\mathrm{Co}^{+2}$ (II) in tetrahedral form and $\mathrm{Co}^{+3}$ (III) [3]. Is an important p-type semiconductor with direct optical bandgaps at 1.48 and $2.19 \mathrm{eV}$, and resistance to chemical and physical impacts [6]. However, the performance of thin films in general, and that of $\mathrm{Co} 3 \mathrm{O} 4$ in particular, is most often dictated by the need for an increasingly high refractive index, an absorption coefficient as low as possible and a more polished surface. However, all this was only feasible with the technological advances recorded in the field of thin film deposition by the use of several physical deposition techniques such as reactive sputtering [7], evaporation by beam of electrons [8] and arc deposition $[9,10]$. Also, it has become imperative to master the production processes of such materials, as well as the influence of the various parameters that imprint its properties on the finished material. Indeed, the limits of use of a given material are often the limits of its properties. Among these deposition techniques, the spray pyrolysis process appeared to us to be one of the simplest and most efficient thin film production methods in view of the (crystalline) quality ratio of the layers obtained with regard to cost price. As part of this work, we were interested in the study of the influence of the production temperature on the physicochemical, optical and electrical properties of thin films of $\mathrm{Co} 3 \mathrm{O} 4$ obtained by the spray pyrolysis technique. To this end, we have developed a series of samples, deposited on glass substrates heated to processing temperatures $\left(300^{\circ} \mathrm{C}, 350^{\circ} \mathrm{C}\right.$ and $\left.400^{\circ} \mathrm{C}\right)$.

\section{Experimental procedure}

\subsection{Preparation of cobalt oxide substrates}

$\mathrm{Co} 3 \mathrm{O} 4$ thin films were prepared from cobalt chloride hexahydrate $\mathrm{CoCl} 2.6 \mathrm{H} 2 \mathrm{O}$. Finally, methanol is poured into the solution to obtain a transparent solution of pink color and slightly viscous. The glass substrates were heated to the necessary processing temperatures $\left(300^{\circ} \mathrm{C}\right.$, $350^{\circ} \mathrm{C}$ and $400^{\circ} \mathrm{C}$ ) on a solar oven (Figure 1). The solution produced is mechanically sprayed onto hot glass substrates. To achieve the desired thickness, the deposition time is varied between 3 and $4 \mathrm{~min}$, this period is expressed in several time intervals in order to give the layer sufficient time to crystallize. By placing the glass substrate on the heating plate of the oven under the crystallization temperature, then turn on the air nebulizer, then spray the solution for four

minutes, then stop for a while until the substrate returns to its temperature, and we repeat the 
process again until we obtain the required thickness. During this elaboration the temperature and followed by a thermocouple with a temperature range between $" 0^{\circ} \mathrm{C}$ to $1300^{\circ} \mathrm{C}$ ".

According to the work presented by several authors, Bougrine, A., and al. [11], Chamberlin, R. and al. [12] Abbas, S. and al. [13], the spray pyrolysis method gives a more or less homogeneous product so that it cannot modify the properties from one zone to another. Especially since the spraying process is perpendicular to the substrate so that the solution is evenly distributed over the entire surface of the substrate. In addition to the temperature uniformity of the substrate on the hotplate.

Finally, after having developed the thin layers of $\mathrm{Co} 3 \mathrm{O} 4$ (Figure 2), their structural, optical and electrical microstructural characterization is then carried out.

\subsection{Characterization}

X-ray diffraction (ARL TM EQUINOX 100 X-ray), UV-visible spectrophotometry (Cary Series uv-vis-NIR Spectrophotometer) and Hall effect measurement system (Ecopia HMS3000) are the main analytical techniques. implemented in this study. By exploitation of DRX spectra, we can access the determination of the average grain size in a thin layer. By assuming that the grains are spherical, the relation of Scherrer $[14,15]$, allows the determination of the mean diameter through the following expression:

$$
D_{(n m)}=\frac{0.90 \cdot \lambda}{\beta \cos \theta}
$$

Hence, $\mathrm{D}$ - the mean grain diameter, $\lambda$ - the wavelength of the incident radiation $(\lambda=$ $1.54056 \AA$ ), $\beta$ - the width at mid-height of the diffraction peak, $\theta$ - the diffraction angle. The thickness of the deposits is measured with a mechanical probe profilometer placed on an antivibration plate in an air-conditioned room. The measured thicknesses of our films (Co3O4) were between $187 \mathrm{~nm}$ and $195 \mathrm{~nm}$. From the values of the extinction coefficient $\mathrm{k}$ of the thin film, obtained by ellipso-metric measurements, the absorption coefficient $\alpha$ can be calculated, using the following relationship:

$$
\alpha=4 \pi k / \lambda
$$

The determination of the optical gap Eg is based on the model proposed by Tauc $[15,16]$, where Eg is related to the absorption coefficient by:

$$
(\alpha E)^{1 / 2}=A\left(h v-E_{g}\right)
$$


$\mathrm{A}$ is a constant reflecting the degree of disorder of the amorphous solid structure, Eg is expressed in $\mathrm{eV}, \mathrm{E}=\mathrm{h} v$ is the energy of the photon in $\mathrm{eV}$.

Due to the double presence of distinct phases, and the fact that no alloy was formed as indicated by XRD analysis; it is difficult to speak of a single gap in such a material, that is why we introduce a definition of an effective bandgap Egeff expressed as [17]:

$$
E_{g . e f f}=(1-x) E_{g 1}+x E_{g 2}
$$

To calculate the resistivity of our samples we used the principle of the Hall effect. This principle is based on two forces: Lorentz magnetic force and Hall electrical force in a semiconductor carrying a current and subjected to a magnetic field, hence the basic physical principle on which the Hall effect is based is the Lorentz force [18]. We used the Ecopia HMS3000 system which has a magnet producing a $0.55 \mathrm{~T}$ field to which the sample is subjected during electrical measurements using a dedicated holder. The device, using a sample holder of four tips arranged in a square and connected to a generator to perform the electrical measurements, is a complete system for measuring resistivity, Hall coefficient, concentration of carriers and their mobility. For our rectangular-shaped samples, the technique consists in taking four-point contacts A, B, C and D which alternately make it possible to inject a current Ih (in $\mathrm{mA}$ ) between two contacts and to measure a voltage Um (in V) between them. two others. By placing the contacts symmetrically (perfect square) and by taking the average of the different voltages Um measured, we can deduce an average resistance $\mathrm{Rm}$ (in $\Omega$ ) which will make it possible to determine the resistivity $\rho(\Omega . \mathrm{cm})$ of the thin film analyzed of thickness e (in $\mathrm{cm}$ ) by the following relation:

$$
\rho=\frac{\pi \cdot e R_{m}}{\ln (2)}
$$

In order to determine the number of free carriers $\mathrm{n}$ ( or $\mathrm{p}$ ) (in $\mathrm{cm}^{-3}$ ), it is necessary to measure the Hall voltage $\mathrm{U}_{\mathrm{h}}$ taken between two contacts as soon as a current $\mathrm{I}_{\mathrm{H}}$ is applied between the other two under the action a magnetic field $\mathrm{B}$ of 0.55 Tesla perpendicular to the sample. By permuting the orientation of this magnetic field, and by averaging the different measurements for each of these permutations, we can obtain the value of the average Hall voltage $U_{h m}$ (in V) and determine $\mathrm{n}$ (or p) as well as the nature of the free carriers (electrons or holes) via the sign associated with the charge $\mathrm{q}$ (in $\mathrm{C}$ ) thanks to the following formula:

$$
n(\text { oup })=\frac{I_{H} \cdot B}{ \pm q \cdot U_{h m} \cdot e}
$$


Finally, knowing $\mathrm{n}$ and $\rho$, we can deduce the electronic mobility $\mu$ (in $\mathrm{cm}^{2} \cdot \mathrm{V}^{-1} \cdot \mathrm{s}^{-1}$ ) by the intermediary of relation (6):

$$
\mu=\frac{1}{| \pm q \cdot| \cdot n \cdot p}
$$

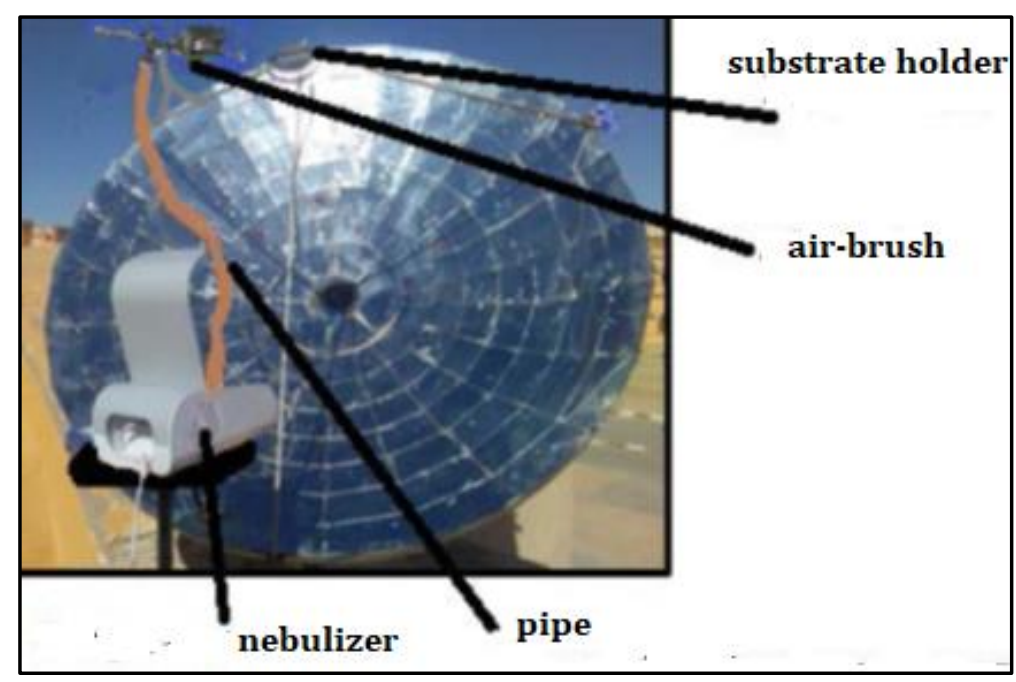

Figure 1. Experimental setup used

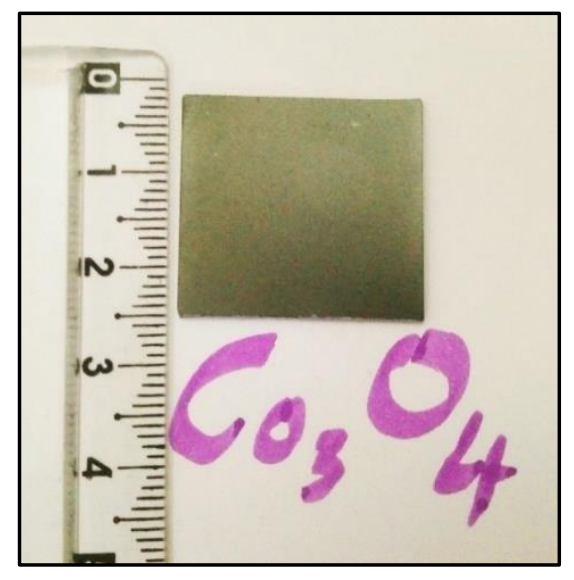

Figure 2. Substrate $\mathrm{Co} 3 \mathrm{O} 4$

\section{Results and Discussions}

\subsection{X-Ray Diffraction}

Figure 3 shows that, all the films show diffraction peaks at $2 \theta=18.86^{\circ}$ and $36.59^{\circ}$ respectively, correspond to the planes ((111) and (311) respectively), indicating the formation of crystals of a only $\mathrm{Co} 3 \mathrm{O} 4$ material in the cubic structure, and all diffraction peaks in this model agree well with the standard map (JCPDS map No. 96-153-8532). We also noticed that in the low temperatures of the substrate, the plane (311) as preferential orientation, is a dominant plane 
(especially in the case of temperatures $300^{\circ} \mathrm{C}$ and $350^{\circ} \mathrm{C}$, on the other hand the plane (111) is the dominant plane in higher substrate temperatures $\left(400^{\circ} \mathrm{C}\right)$. These results are consistent with the results of several authors who have worked on Co3O4, K. Klepper and al. [19] Y. Jiang and al. [20]. Zhan and al. [21], Abbas, S and al. [13], R. Manogowri and al. [22], A. Louardi and al. [23]. In this case, the surface energy of the (111) plane was lowest. When the temperature of the substrate increases, and the grains of the thin films will then have a very strong tendency to orient themselves coherently during the preparation of the sample towards this plane. The average size of the crystallites D at peak (111) increases by $34.64 \mathrm{~nm}$ at $49.19 \mathrm{~nm}$ with increasing substrate temperature up to $350^{\circ} \mathrm{C}$, then decreases to $34.65 \mathrm{~nm}$ at temperature $400^{\circ} \mathrm{C}$. This can be attributed to the fact that a high temperature of the substrate increases the formation of polycrystalline film with a better crystalline [23, 24]. The values of the preferential orientation TC (hkl), of the planes (111) and (311) increase continuously with the increase in the production temperature, but the values of the plane (311) experience a decrease after $350^{\circ} \mathrm{C}$ (Table 1). In addition, we have found the plane (311) as the preferential orientation for the entire temperature range and (111) exhibits a preferential orientation than in higher substrate temperatures $\left(350^{\circ} \mathrm{C}\right.$ to $400^{\circ} \mathrm{C}$ ). This phenomenon can be attributed to the increase in the density of oxygen and the decrease in the density of cobalt in thin films. Several authors, M. Manickam and al. [25], Abbas, S. and al. [13], N. Kouidri and al. [26], have found the same results. The dislocation density $\delta$ and the deformation $\varepsilon$ of $\mathrm{Co} 3 \mathrm{O} 4$ films are reduced with increasing temperature up to $350^{\circ} \mathrm{C}$, after this temperature, the values of $\delta$ and $\varepsilon$ increase with increasing temperature (Table 1$)$. This observation is the same for the plans (111) and for the plans (311). We observe an inverse relationship with the size of the crystallites.

Table 1. The acoustic parameters of Co3O4 (T)

\begin{tabular}{|c|c|c|c|c|c|c|c|c|}
\hline & $\mathrm{hkl}$ & $2 \theta\left[^{\circ}\right]$ & $\mathrm{d}[\AA]$ & $\mathrm{D}[\mathrm{nm}]$ & $\mathrm{a}[\AA]$ & $\begin{array}{c}\delta .10^{14} \\
{[\text { line/m }}\end{array}$ & $\varepsilon .10^{-3}$ & $\mathrm{Tc}(\mathrm{hkl})$ \\
\hline $\mathrm{T}=300^{\circ} \mathrm{C}$ & $(111)$ & 18.75 & 4.7 & 34.64 & 8.15 & 8.33 & 11.62 & 0.095 \\
\cline { 2 - 10 } & $(311)$ & 36.42 & 2.45 & 27.61 & 8.14 & 13.11 & 15.15 & 0.013 \\
\hline $\mathrm{T}=350^{\circ} \mathrm{C}$ & $(111)$ & 18.86 & 4.67 & 49.19 & 8.09 & 4.13 & 8.19 & 0.098 \\
\cline { 2 - 10 } & $(311)$ & 36.49 & 2.45 & 27.35 & 8.14 & 13.37 & 15.3 & 1.61 \\
\hline $\mathrm{T}=400^{\circ} \mathrm{C}$ & $(111)$ & 18.87 & 4.68 & 34.65 & 8.1 & 8.33 & 11.62 & 0.105 \\
\cline { 2 - 9 } & $(311)$ & 36.27 & 2.48 & 27.21 & 8.21 & 13.51 & 15.36 & 0.014 \\
\hline
\end{tabular}




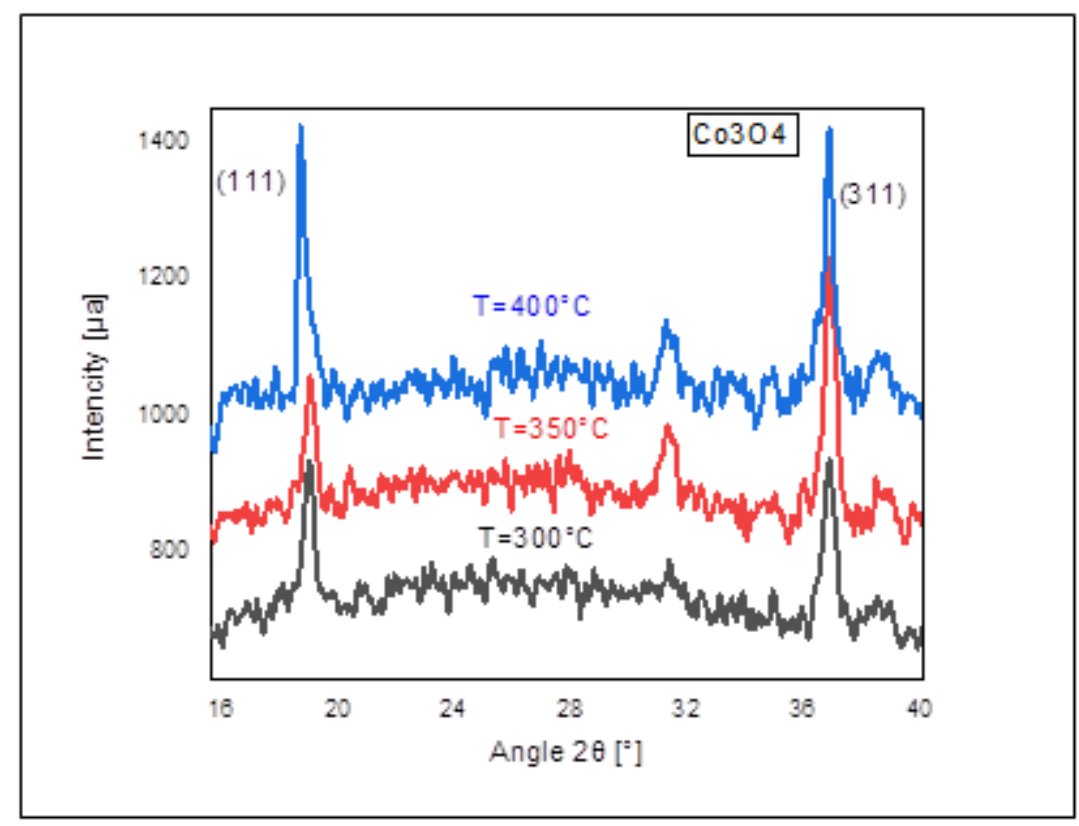

Figure 3. Acoustic parameters of $\mathrm{Co} 3 \mathrm{O} 4$ thin films as a function of temperature

Figure 4 shows typical absorbance spectra recorded for thin films of $\mathrm{Co} 3 \mathrm{O} 4$ at different processing temperatures. In this figure, we can notice that the thin films deposited are completely transparent in the visible and start to absorb in the range between 300 and $350 \mathrm{~nm}$, that is to say in the near ultraviolet. With the increase in temperature, there is a shift in the absorption threshold towards longer lengths indicating the increase in the gap of the Co3O4 films.

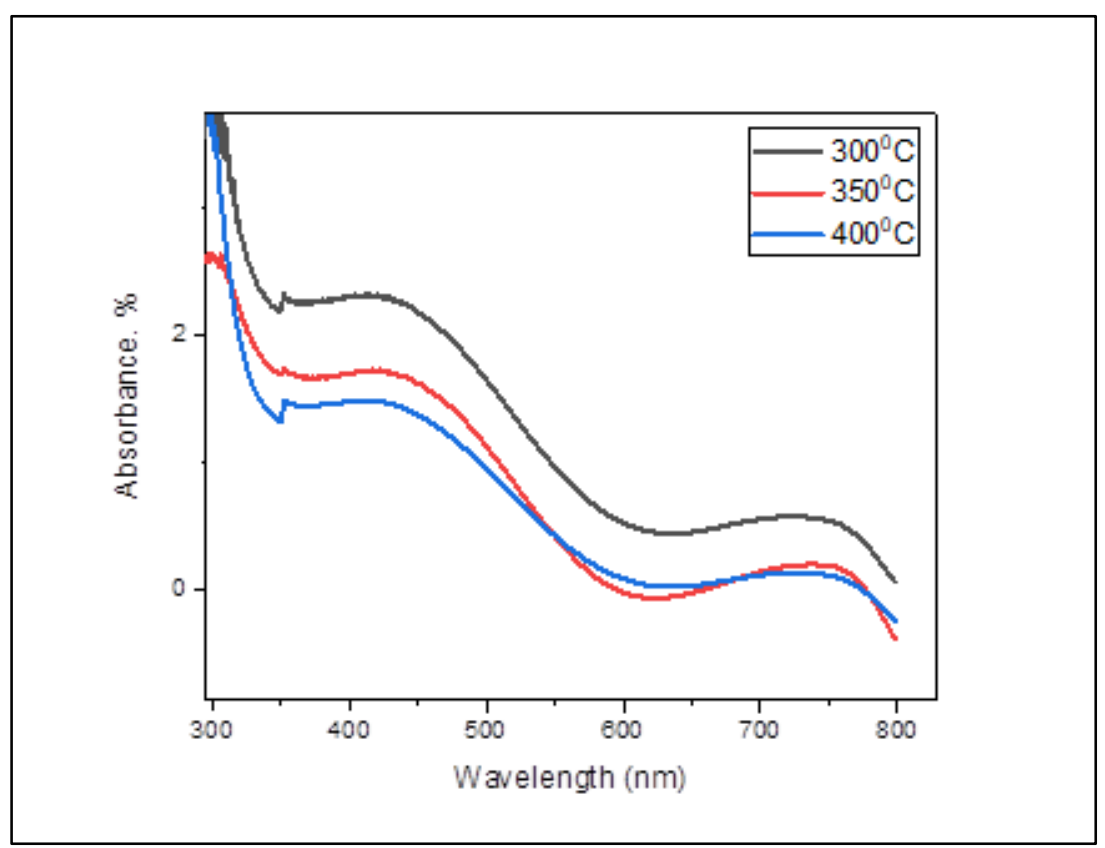

Figure 4. Absorbance spectra of $\mathrm{Co} 3 \mathrm{O} 4$ thin films as a function of processing temperatures 


\subsection{Optical properties}

Figure 5 represents the evolution of the optical gaps of thin films in $\mathrm{Co} 3 \mathrm{O} 4$. The values of two direct forbidden bands were named Eg1 (lower energy region) and Eg2 (higher energy region). The multiple optical gap energies for $\mathrm{Co} 3 \mathrm{O} 4$ films may suggest the possibility of valance tape degeneration [27]. The values of the effective optical gaps vary between $(1,923 \mathrm{eV}$ and $2,074 \mathrm{eV}$ ). It is clear to observe that all the values of the optical gaps are increased with the evolution of the temperature. As we have seen in Table 2, the values of Eg1 and Eg2 pass respectively from $1.720 \mathrm{eV}$ to $1.816 \mathrm{eV}$ and from $2.547 \mathrm{eV}$ to $3.073 \mathrm{eV}$, and these values are in good agreement with the results of other authors who work on the same axis Abbas, S and al. [13], [25, 28]. This change could be attributed to changes in the quality of $\mathrm{Co} 3 \mathrm{O} 4$ films with increasing substrate temperature [23]. The energy of the forbidden bands increases the temperature of the substrate, when the oxygen atoms are increased, the holes fill the states in the valence band, which leads to the shift of the Fermi level towards the low energies. The band gap measured from the inter-band absorption changes to a higher energy (blue shift) [26]. Figure 6 represents the evolution of the values of the Urbach energies as a function of the production temperature, it is clear to note that the values of the Urbach energies decrease with the increase in temperature (change inversely with the optical band gap). This means that when the temperature of the substrate increases, the influence of the tails of the bands on the energy of the band gap becomes weaker [29].

Table 2. Optical results of the thin films produced.

\begin{tabular}{|c|c|c|c|c|c|}
\hline & $\mathrm{Eg} 1[\mathrm{eV}]$ & $\mathrm{Eg} 2[\mathrm{eV}]$ & Egef $[\mathrm{eV}]$ & Eu1 $[\mathrm{meV}]$ & Eu2 $[\mathrm{meV}]$ \\
\hline $\mathrm{T}=300^{\circ} \mathrm{C}$ & 1.932 & 1.720 & 2.547 & 245.01 & 360.81 \\
\hline $\mathrm{T}=350^{\circ} \mathrm{C}$ & 2.004 & 1.781 & 2.680 & 180.29 & 352.94 \\
\hline $\mathrm{T}=400^{\circ} \mathrm{C}$ & 2.074 & 1.816 & 3.073 & 162.20 & 330.32 \\
\hline
\end{tabular}




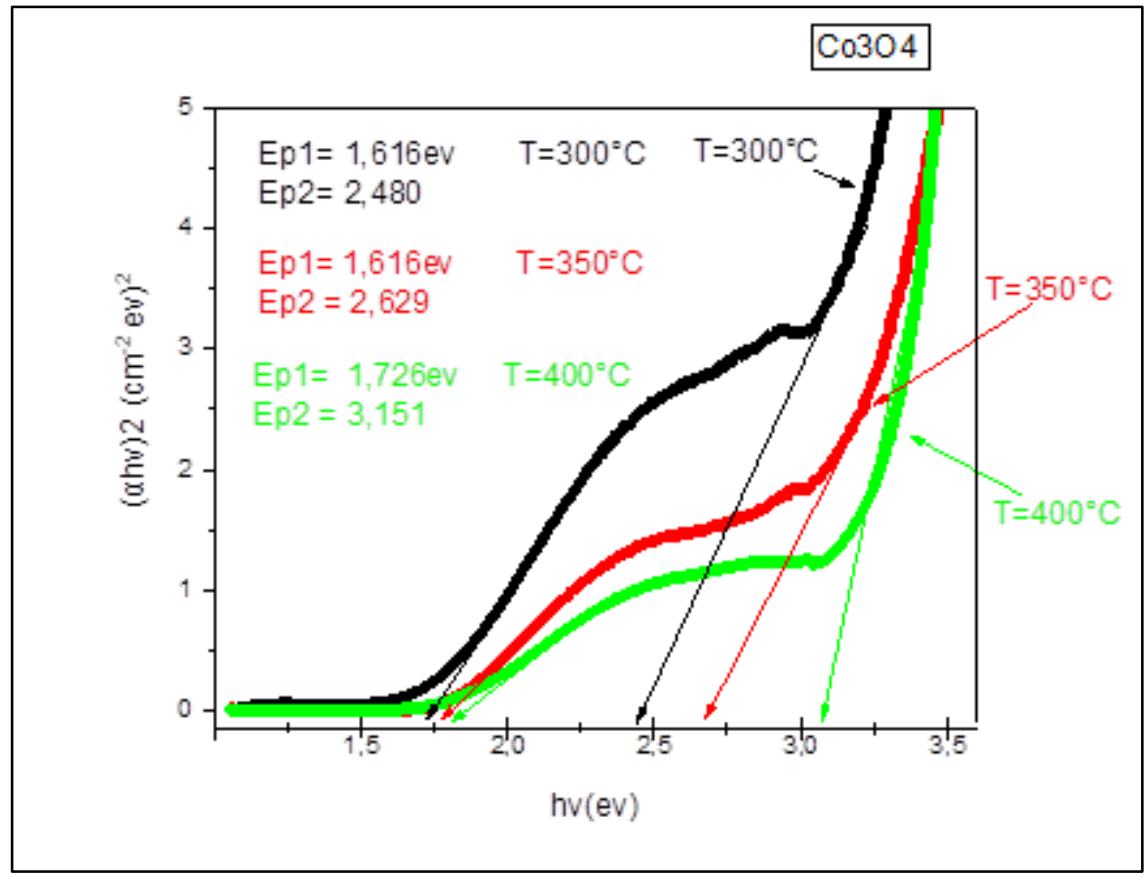

Figure 5. Optical gaps of $\mathrm{Co} 3 \mathrm{O} 4$ thin films

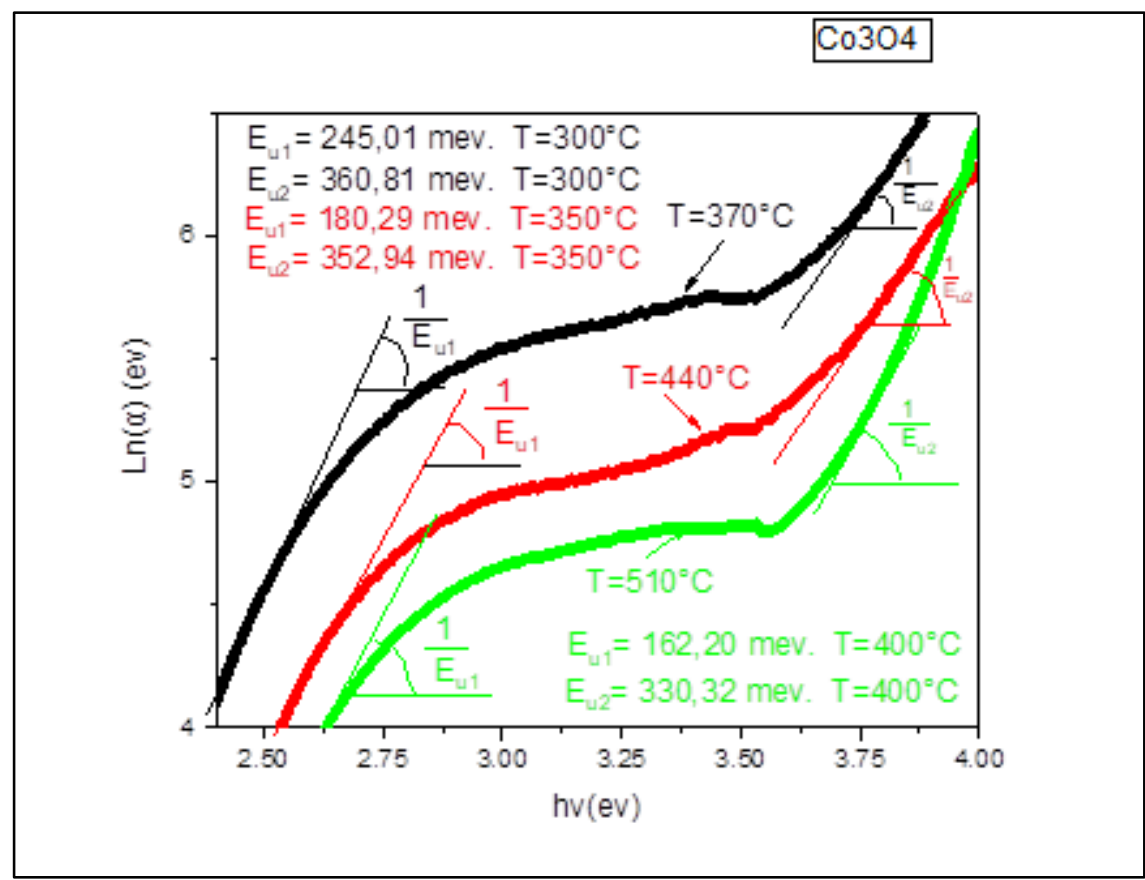

Figure 6. The Urbach parameters (Eu) of $\mathrm{Co} 3 \mathrm{O} 4$ thin films

\subsection{Electrical properties}

In order to verify the quality of our contacts, the I $-\mathrm{V}$ measurements (Figure 7) were carried out at room temperature between the contacts (ab, bc, cd and da) on the surfaces of Co3O films having different thicknesses $(360,332$ and $381 \mathrm{~nm})$. The trace $\mathrm{I}-\mathrm{V}$ at the level of the terminals ( $a b, b c, c d$ and da) presents in each of the configurations a linear form. This fact means that the contacts are of the ohmic type, thus making it possible to measure the 
transport properties of our samples.

Table 3. Electrical results of Co3O4 as a function of temperature.

\begin{tabular}{|l|l|l|l|l|l|}
\hline & $\mathrm{n}\left[\mathrm{cm}^{-3}\right]$ & $\mu\left[\mathrm{cm}^{2} / \mathrm{V} . \mathrm{s}\right]$ & $\sigma\left[(\Omega . \mathrm{cm})^{-1}\right]$ & $\rho[(\Omega . \mathrm{cm})]$ & $\mathrm{e}[\mathrm{nm}]$ \\
\hline $300^{\circ} \mathrm{C}$ & $6.935 \mathrm{E}+18$ & $3.967 \mathrm{E}+02$ & 1.853 & 1.431 & 360 \\
\hline $350^{\circ} \mathrm{C}$ & $2.355 \mathrm{E}+18$ & 1.430 & 1.090 & 1.853 & 332 \\
\hline $400^{\circ} \mathrm{C}$ & $2.355 \mathrm{E}+18$ & $6.292 \mathrm{E}-01$ & 1.431 & 1.853 & 381 \\
\hline
\end{tabular}

Table 3 groups together the data deduced for Hall mobility $\mu$, the concentration of free electrons $n$ and the resistivity $\rho$ measured at ambient temperature. The study shows that the conduction is p-type for all $\mathrm{Co} 3 \mathrm{O} 4$ thin films. The measurements show on the one hand, the more the production temperature increases, the more mobility decreases and that, on the other hand, $\mathrm{Co3O} 4$ films are relatively conductive $(10 \Omega . \mathrm{cm})$.

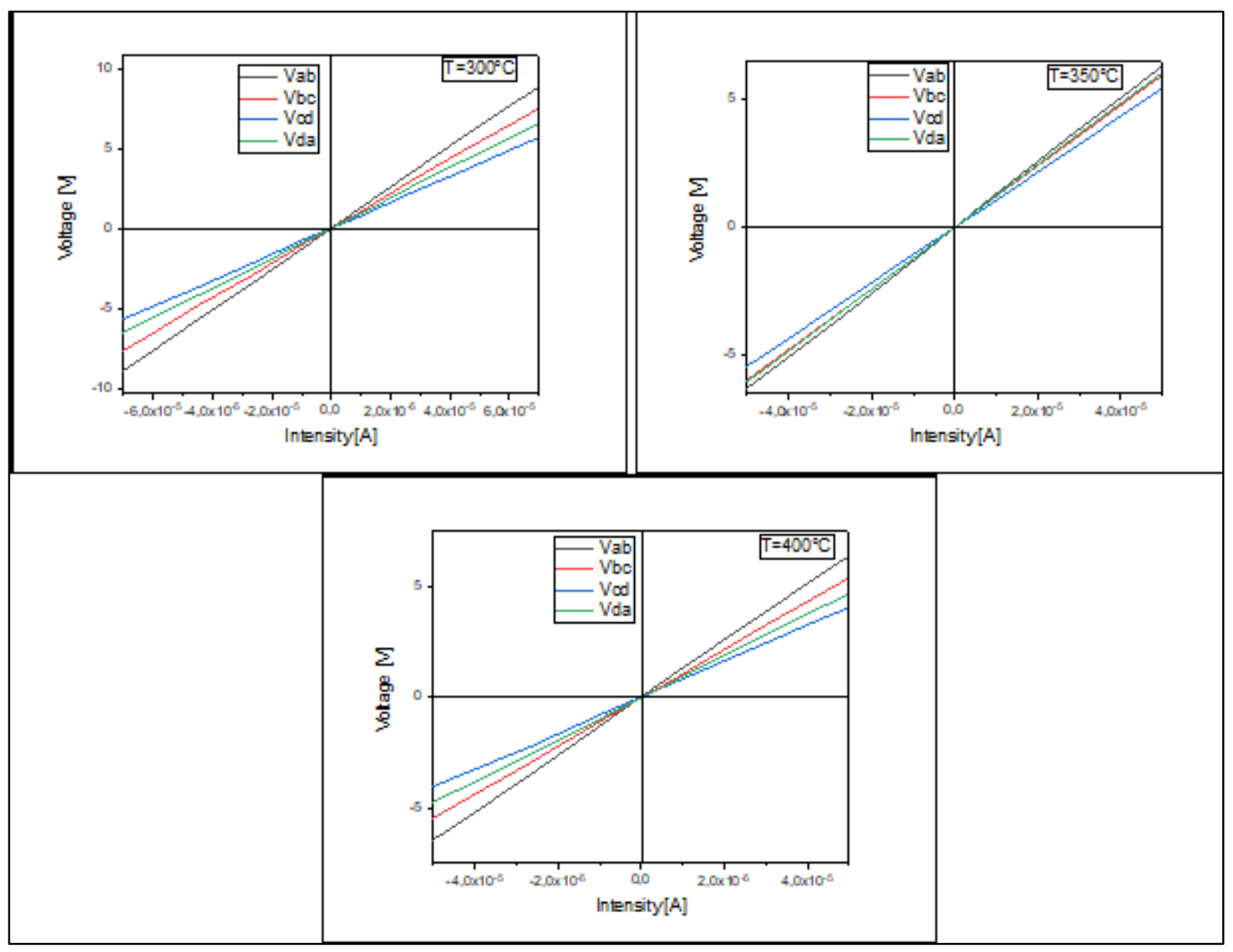

Figure 7. Curves $\mathrm{I}=\mathrm{f}(\mathrm{V})$ of the contacts (terminals ab, bc, cd and da) of Co3O4 thin films

This consequently leads to a reduction in the lifetime of the carriers which then 
generates a decrease in the mobility and the concentration of the carriers, ultimately leading to a low conductivity of the films, which is high enough to constitute a good electrode material. super capacitor. This is because stoichiometric $\mathrm{Co} 3 \mathrm{O} 4$ is an insulator and its electrical properties depend on the amount of oxygen adsorbed on the surface. A similar behavior of electrical conductivity has been reported by Patil et al. and Gencyllmaz and al. $[25,30]$.

\section{Conclusion}

A solar concentrator used as an oven has been successfully produced. Thanks to this device, the pyrolysis spray method was applied. The oxides used (cobalt oxide) are sprayed by a nebulizer and its airbrush, under the effect of pressure which transforms the starting solution into a jet of very fine droplets. The good optical characterization of the glasses which adapts well for their transparency to thin films, and their resistance to heating up to $600^{\circ} \mathrm{C}$, led us to choose rectangular glass slides of $1.5 \mathrm{~cm} \times 5 \mathrm{~cm}$, and thickness equal to $1 \mathrm{~mm}$. Very good quality thin films of cobalt oxide ( $\mathrm{Co} 3 \mathrm{O} 4)$ are produced at various temperatures $\left(300^{\circ} \mathrm{C}, 350^{\circ} \mathrm{C}\right.$ and $\left.400^{\circ} \mathrm{C}\right)$. The thin films produced are nanocrystalline with a face-centered cubic CFC structure. Where the (311) plane is a dominant plane in all cobalt thin films except films produced at high temperatures, where the dominant plane is (111). All the deposits in planes (311) and (404) are polycrystalline with values of the preferential orientation varying between (0.014 and 1.61). The maximum value of the grain size reaches a value of 49.19 $\mathrm{nm}$, for an elaboration temperature of $350^{\circ} \mathrm{C}$. Our developed products have presented dislocation density values that vary between $8.33 \times 10^{14}\left[\right.$ line $\left./ \mathrm{m}^{2}\right]$ and $13.51 \times 10^{14}\left[\right.$ line $\left./ \mathrm{m}^{2}\right]$, and strain values ranging between $8.19 \times 10^{-3}[\%]$ and $15.36 \times 10^{-3}[\%]$. The effective optical gap values which vary between $(2.547 \mathrm{eV}$ and $3.0731 \mathrm{eV})$, with variation of the Urbach parameters between $162.20 \mathrm{meV}$ and $360.81 \mathrm{meV}$. Finally our elaborated films are relatively insulating conductors, with values of electrical conductivities between $\left(1.090\left[(\Omega . \mathrm{cm})^{-1}\right]\right.$ and $\left.1.853\left[(\Omega . \mathrm{cm})^{-1}\right]\right)$, and resistivities between $(1.431[(\Omega . \mathrm{cm})]$ and $1.853[(\Omega . \mathrm{cm})])$

\section{References}

[1] M. Dresselhaus and I. Thomas, "Alternative energy technologies," Nature, vol. 414, no. 6861, pp. 332-337, 2001.

[2] K. Chidambaram, L. Malhotra, and K. Chopra, "Spray-pyrolysed cobalt black as a high temperature selective absorber," Thin Solid Films, vol. 87, no. 4, pp. 365-371, 1982. 
[3] U. Stimming, S. Singhal, and H. Tagawa, "Proceedings of the Fifth International Symposium on Solid Oxide Fuel Cells (SOFC-V)," 1997: The Electrochemical Society.

[4] J. Cox, D. D. Wagman, V. A. Medvedev, and D. P. Wagman, CODATA key values for thermodynamics. Hemisphere Pub, 1989.

[5] L. Mendoza Blanco, "Revêtements protecteurs à base d'oxyde de cobalt, de titane ou de cérium pour la cathode de nickel des piles à combustible à carbonates fondus," Paris 6 , 2003.

[6] A. Gulino, P. Dapporto, P. Rossi, and I. Fragalà, "A novel self-generating liquid MOCVD precursor for Co3O4 thin films," Chemistry of materials, vol. 15, no. 20, pp. 3748-3752, 2003.

[7] D. Mardare and P. Hones, "Optical dispersion analysis of $\mathrm{TiO} 2$ thin films based on variable-angle spectroscopic ellipsometry measurements," Materials Science and Engineering: B, vol. 68, no. 1, pp. 42-47, 1999.

[8] T. Modes, B. Scheffel, C. Metzner, O. Zywitzki, and E. Reinhold, "Structure and properties of titanium oxide layers deposited by reactive plasma activated electron beam evaporation," Surface and Coatings Technology, vol. 200, no. 1-4, pp. 306-309, 2005.

[9] M. Zhang, G. Lin, C. Dong, and L. Wen, "Amorphous TiO2 films with high refractive index deposited by pulsed bias arc ion plating," Surface and Coatings Technology, vol. 201, no. 16-17, pp. 7252-7258, 2007.

[10]Z. Zhao, B. K. Tay, and G. Yu, "Room-temperature deposition of amorphous titanium dioxide thin film with high refractive index by a filtered cathodic vacuum arc technique," Applied optics, vol. 43, no. 6, pp. 1281-1285, 2004.

[11] A. Bougrine, A. El Hichou, M. Addou, J. Ebothé, A. Kachouane, and M. Troyon, "Structural, optical and cathodoluminescence characteristics of undoped and tin-doped $\mathrm{ZnO}$ thin films prepared by spray pyrolysis," Materials Chemistry and Physics, vol. 80, no. 2, pp. 438-445, 2003.

[12] R. Chamberlin and J. Skarman, "Chemical spray deposition process for inorganic films," Journal of the Electrochemical Society, vol. 113, no. 1, p. 86, 1966.

[13] S. Abbas, A. Aboud, M. Irfan, and S. Alam, "Ser," Mater. Sci. Eng., vol. 60, p. 012058, 2014

[14]B. D. Cullity, "Elements of X-ray diffraction, Addison," Wesley Mass, pp. 127-31, 1978.

[15] L. Miao, P. Jin, K. Kaneko, A. Terai, N. Nabatova-Gabain, and S. Tanemura, "Preparation and characterization of polycrystalline anatase and rutile $\mathrm{TiO} 2$ thin films by $\mathrm{rf}$ magnetron sputtering," Applied Surface Science, vol. 212, pp. 255-263, 2003. 
[16] M. Abdel-Aziz, I. Yahia, L. Wahab, M. Fadel, and M. Afifi, "Determination and analysis of dispersive optical constant of $\mathrm{TiO} 2$ and Ti2O3 thin films," Applied surface science, vol. 252, no. 23, pp. 8163-8170, 2006.

[17] N. Talebian and M. Kheiri, "Sol-gel derived nanostructured nickel oxide films: effect of solvent on crystallographic orientations," Solid state sciences, vol. 27, pp. 79-83, 2014.

[18]E. H. Putley, The Hall effect and related phenomena. Butterworths, 1960.

[19] K. Klepper, O. Nilsen, and H. Fjellvåg, "Growth of thin films of Co3O4 by atomic layer deposition," Thin Solid Films, vol. 515, no. 20-21, pp. 7772-7781, 2007.

[20] Y. Jiang, Y. Wu, B. Xie, Y. Xie, and Y. Qian, "Moderate temperature synthesis of nanocrystalline $\mathrm{Co} 3 \mathrm{O} 4$ via gel hydrothermal oxidation," Materials chemistry and physics, vol. 74, no. 2, pp. 234-237, 2002.

[21]F. Zhan, B. Geng, and Y. Guo, "Porous Co3O4 nanosheets with extraordinarily high discharge capacity for lithium batteries," Chemistry-A European Journal, vol. 15, no. 25, pp. 6169-6174, 2009.

[22] R. Manogowri, R. M. Mathelane, S. Valanarasu, I. Kulandaisamy, A. B. Fathima, and A. Kathalingam, "Effect of annealing temperature on the structural, morphological, optical and electrical properties of Co $3 \mathrm{O} 4$ thin film by nebulizer spray pyrolysis technique," Journal of Materials Science: Materials in Electronics, vol. 27, no. 4, pp. 3860-3866, 2016.

[23]A. Louardi, A. Rmili, F. Ouachtari, A. Bouaoud, B. Elidrissi, and H. Erguig, "Characterization of cobalt oxide thin films prepared by a facile spray pyrolysis technique using perfume atomizer," Journal of Alloys and Compounds, vol. 509, no. 37, pp. 91839189, 2011.

[24] A. U. Mane and S. Shivashankar, "MOCVD of cobalt oxide thin films: dependence of growth, microstructure, and optical properties on the source of oxidation," Journal of crystal growth, vol. 254, no. 3-4, pp. 368-377, 2003.

[25] O. Gençyılmaz, T. Taşköprü, F. Atay, and İ. Akyüz, "Synthesis, characterization and ellipsometric study of ultrasonically sprayed Co 3 O 4 films," Applied Physics A, vol. 121, no. 1, pp. 245-254, 2015.

[26] N. Kouidri, S. Rahmane, and A. Allag, "Substrate temperature-dependent properties of sprayed cobalt oxide thin films," Journal of Materials Science: Materials in Electronics, vol. 30, no. 2, pp. 1153-1160, 2019.

[27]J. Pal and P. Chauhan, "Study of physical properties of cobalt oxide (Co3O4) nanocrystals," Materials characterization, vol. 61, no. 5, pp. 575-579, 2010. 
[28]L. Kadam and P. Patil, "Thickness-dependent properties of sprayed cobalt oxide thin films," Materials chemistry and physics, vol. 68, no. 1-3, pp. 225-232, 2001.

[29] S. J. Ikhmayies and R. N. Ahmad-Bitar, "A study of the optical bandgap energy and Urbach tail of spray-deposited CdS: In thin films," Journal of Materials Research and Technology, vol. 2, no. 3, pp. 221-227, 2013.

[30]P. Patil, L. Kadam, and C. Lokhande, "Preparation and characterization of spray pyrolysed cobalt oxide thin films," Thin Solid Films, vol. 272, no. 1, pp. 29-32, 1996. 